\title{
Refinación de PETRóleo en MÉXico Y PERSPECTIVA DE LA REFORMA ENERGÉTICA
}

\author{
Daniel Romo ${ }^{1}$
}

Fecha de recepción: 26 de febrero de 2016. Fecha de aceptación: 11 de julio de 2016.

\begin{abstract}
RESUMEN
El presente trabajo analiza las condiciones de la industria de la refinación en México y los factores que enmarcan su relanzamiento en el contexto de la Reforma Energética de 2013. Para ello, se identificaran los principales retos que las empresas de refinación en el mundo deben atender para permanecer en el mercado, evaluando el caso particular de Estados Unidos y Canadá. De igual manera, se realizará un diagnóstico sobre la refinación en México, para identificar sus principales determinantes, para finalmente, llevar a cabo un análisis de sus perspectivas, considerando el rol de la iniciativa privada en el mercado abierto y de Petróleos Mexicanos (Pemex), como comodín en las áreas en donde las compañías privadas no participen.
\end{abstract}

Palabras clave: petróleo, refinación, Reforma Energética, mercado mundial, consumo energético, inversiones.

Clasificación JEL: O13, Q41, Q43, Q48.

\section{Oil Refining in Mexico and Prospects FOR THE ENERGY ReFORM}

\begin{abstract}
This paper analyzes the conditions facing the oil refining industry in Mexico and the factors that shaped its overhaul in the context of the 2013 Energy Reform. To do so, the paper examines the main challenges that refining companies must tackle to stay in the market, evaluating the specific cases of the United States and Canada. Similarly, it offers a diagnosis of refining in Mexico, identifying its principal determinants in order to, finally, analyze its prospects, considering the role of private initiatives in the open market, as well as Petróleos Mexicanos (Pemex), as a placeholder in those areas where private enterprises do not participate.
\end{abstract}

Key Words: Oil, refining, Energy Reform, global market, energy consumption, investment.

${ }^{1}$ Instituto Politécnico Nacional, México. Correo electrónico: dromor@ipn.mx 


\section{RAFFINAGE DE PÉTROLE AU MEXIQUE ET PERSPECTIVE DE LA RÉFORME ÉNER- GÉTIQUE \\ Résumé}

Ce travail analyse les conditions de l'industrie du raffinage au Mexique et les facteurs qui encadrent sa relance dans le contexte de la Réforme énergétique de 2013. A cette fin, y sont identifiés les principaux défis auxquels les entreprises de raffinage dans le monde doivent répondre pour rester sur le marché, évaluant le cas particulier des États-Unis et du Canada. De la même manière, il est établi un diagnostic sur le raffinage au Mexique, pour identifier ses principaux déterminants, et pour finalement mener à bien une analyse de ses perspectives, en prenant en compte le rôle de l'initiative privée dans le marché ouvert et de Petróleos Mexicanos (Pemex) comme joker dans les domaines où les compagnies privées ne participent pas.

Mots clés: pétrole, raffinage, Réforme Énergétique, marché mondial, consommation énergétique, investissements.

\section{REFINAMENTO DE PETRÓlEO NO MÉXICO E PERSPECTIVA DA REFORMA ENEGÉTICA \\ Resumo}

O presente trabalho analisa as condiçóes da indústria de refinamento no México e os fatores que emolduram seu relançamento no contexto da Reforma Energética de 2013. Para isso, se identificam os principais desafios que as empresas de refinamento no mundo devem atender para permanecer no mercado, avaliando o caso particular dos Estados Unidos e do Canadá. Da mesma forma, se realiza um disgnotico sobre o refinamento no Mexico, para identificar seus principais determinantes, para, finalmente, se levar a cabo uma análise das suas perspectivas, considerando o papel da iniciativa privada no mercado aberto de Petróleos Mexicanos (Pemex), como coringa nas áreas onde as companhias privadas não participem.

Palavras-chave: petróleo, refinamento, Reforma Energética, mercado mundial, consumo energético, inversóes.

\section{墨西哥炼油及能源改革前景}

摘要

本文分析墨西哥炼油行业的条件以及在2013年能源改革背景下该行业重 新起航的因素。本文以美国和加拿大为例, 指出了国际炼油企业想要在市 场上站稳脚跟应该注意的主要挑战。此外, 本文将对墨西哥炼油业进行剖 析, 探求其决定因素, 并分析其未来前景。在分析中我们将考虑私营企业 在开放市场中的角色以及在私企没有涉足的领域中墨西哥国家石油公司的 角色。

关键词：石油，炼油，能源改革，世界市场，能源消费，投资 


\section{INTRODUCCIÓN}

Al cierre de 2013, el mercado de los refinados mostraba contrastes. Por un lado, existía un adecuado abasto al mercado interno de productos pesados y excesivos volúmenes de combustóleo. Por el otro, el mercado de las gasolinas y diésel no era satisfecho con producción de Petróleos Mexicanos (Pemex). La posibilidad de realizar ampliaciones de infraestructura se había limitado, pues el proyecto de la nueva refinería en Tula, Hidalgo, estaba en duda y lo que se planeaba era la reconfiguración de las unidades de Tula, Salamanca y Salina Cruz. Esta situación limitaba la capacidad de oferta de Pemex en los siguientes ańos y ponía en manos de las importaciones la posibilidad de abastecer el mercado interno.

En ese contexto, se da paso a la apertura de la industria de la refinación, que tiene como objeto su relanzamiento. Sin embargo, ello está sujeto a un conjunto de retos que son tema de análisis en este trabajo, y que serán fundamentales en el comportamiento de esa industria en los años por venir. El documento aquí elaborado parte de un primer apartado de consideraciones generales sobre la industria de la refinación mundial, para después en un segundo, estudiar su desempeño en el mercado de Estados Unidos y Canadá, tomando en cuenta que más de las empresas que tienen o pueden tener relación de negocios en México, realizan operaciones también en esas naciones. En un tercer apartado, se presenta el diagnóstico realizado sobre la refinación en el país, con base en el uso de herramientas de análisis industrial a lo largo de su cadena de valor para, finalmente, identificar los principales retos por enfrentar en el nuevo escenario de un mercado abierto a la competencia.

\section{LA INDUSTRIA DE LA REFINACIÓN EN EL MUNDO}

La industria de la refinación es estratégica para la economía, ya que brinda la oportunidad de añadir valor al petróleo. Sus destilados son base de abastecimiento de un sinnúmero de actividades que realiza el ser humano, entre las que sobresale el transporte, la generación de electricidad y las actividades que demandan calor en sus procesos.

En general, la industria de la refinación es intensiva en capital, en donde el tamaño y complejidad tecnológica, junto con el costo salarial y las regulaciones ambientales, son relevantes para su viabilidad. Esta industria está constituida por un conjunto de grandes plantas de producción continua, en las que el petróleo crudo es separado en diferentes fracciones; por ejemplo, el aceite es 
procesado física y químicamente para elaborar productos terminados, que van desde los muy livianos -como el gas licuado del petróleo- hasta los más pesados -como los asfaltos o el coque de petróleo-. La industria de la refinación también comprende el transporte y almacenamiento de los productos elaborados, así como su entrega a los consumidores a través de sus puntos de distribución.

Ante las condiciones de mercado, la industria de la refinación ha enfrentado distintos momentos como un exceso de capacidad de producción a finales de los años ochenta y principios de los años noventa o el colapso de los márgenes de ganancia en los primeros ańos del decenio pasado.

En general, la industria de la refinación internacional continúa reinventándose, ya sea ampliando su capacidad, renovándola y/o actualizándola, a fin de elevar su vida útil y competitividad, con procesos más enfocados a productos de mayor valor agregado, como la gasolina y el diésel, y limitando la elaboración de derivados pesados; empleando tecnologías flexibles para el procesamiento del petróleo crudo ante los problemas de su disposición en las refinerías y la volatilidad en su precio.

Ha enfrentado también, márgenes de refinación estrechos y volátiles que han motivado una mayor eficiencia operativa, la instrumentación de acciones para la optimización de la energía empleada, la automatización de procesos y la contratación de personal calificado, entre otras medidas; se ha enfocado a ofertar el tipo de derivados de petróleo que demanda el mercado: más limpios, eficientes y con los estándares de calidad requeridos; a adaptarse a la tendencia de coexistir con los combustibles sustitutos, ${ }^{2}$ como el gas natural en Estados Unidos; a adoptar las normas ambientales en sus procesos, que en algunos casos representan inversiones poco rentables; a elaborar derivados de mejor calidad en su combustión, bien a través de la incorporación de mejoras tecnológicas como es el caso de gasolina con alta entalpia de evaporación que permite mejorar su eficiencia al enfriar la mezcla de combustible durante el proceso de inyección, o simplemente a través de la mezcla de sus productos con líquidos obtenidos de fuentes renovables, como el etanol.

Asimismo, ante los retornos de largo plazo, las compañías refinadoras han buscado esquemas de acceso a financiamiento acudiendo a los mercados de valores o préstamos bancarios, pero también capitalizando sus beneficios derivados del periodo de altos precios del petróleo, como ocurrió entre 2004 y finales de 2014.

2 El boom de la producción de gas natural ha impulsado su empleo, particularmente en el sector transporte. También existe la producción de otros combustibles líquidos tales como los biocombustibles, el gas to liquid o coal to liquid. 
En particular, se han instrumentado estrategias para mejorar la presencia de las compañías de refinación en el mercado. En este punto, destacan las petroleras internacionales, que además de obtener importantes beneficios del negocio de la refinación, poseen robustos sistemas de procesamiento, almacenamiento y transporte de petrolíferos e incluso, en algunos casos, cuentan con una integración en sus actividades de upstream o bien se enfocan solo en la refinación.

El negocio de la refinación es operado en el mundo desde criterios de libre mercado hasta en los que los gobiernos intervienen de manera fundamental. En este último caso, ocurre que algunas unidades operan con baja o nula rentabilidad.

Al cierre de 2014, la demanda total de derivados del petróleo llegó a 92 millones de barriles por día (mmbd) de los cuales $49 \%$ correspondió a naciones de la Organización para la Cooperación y el Desarrollo Económicos (OCDE), quienes mostraron una tendencia decreciente de casi $3 \mathrm{mbd}$ desde el 2008 por efecto de la sacudida económica, siendo el consumo de combustóleo el que registró un mayor ajuste. En cambio en las naciones no OCDE, la demanda de productos petrolíferos se ha robustecido (véase cuadro 1).

Por otro lado, la capacidad de refinación en el mundo hacia el cierre de 2014 fue superior a la demanda de productos petrolíferos y se ubicó en 96.5 mbd, ${ }^{3} 22 \%$ por arriba de la existente en 1980 , siendo los países no oCDE los que mayor incremento registraron. Sobresale la región Asia-Pacífico y la tendencia de naciones del Medio Oriente por ańadir valor a su crudo, y que mayor adición de capacidad instalada han logrado. Esto contrastó con Europa en donde dicha capacidad se redujo en $4.5 \mathrm{mmbd}$ entre 2008 y mediados de 2014 (IEA, 2014).

Entre 1980 y 2014, la capacidad de refinación en Norteamérica se redujo al igual que su contribución al total mundial (véase cuadro 2). Al cierre de 2014, fue de $21.3 \mathrm{mmbd}$, de los cuales Estados Unidos contaba con 84\%, Canadá $9.2 \%$ y México con el $6.8 \%$ restante. El volumen neto de petróleo importado en esa región acumuló un poco más de $4.6 \mathrm{mmbd}$, básicamente por las compras al exterior de Estados Unidos, que gracias a sus excedentes propició que la región sea una exportadora neta de petrolíferos.

La Organización de Países Exportadores de Petróleo (OPEP) estima que más de 9 mmbd de capacidad de destilación primaria será incorporada entre 20142019, de los que más del 92\% será de actualizaciones y ampliaciones de las

3 Al cierre de 2013, el total de estas plantas en operación en el mundo fue superior a las 12 mil unidades. 
Cuadro 1. Demanda de productos petrolíferos en el mundo 1980 y 2014 Millones de barriles por día

\begin{tabular}{|c|c|c|c|c|c|c|c|c|}
\hline \multirow{2}{*}{$\begin{array}{l}\text { Derivados } \\
\text { del petróleo }\end{array}$} & \multicolumn{2}{|c|}{ Europa y Japón } & \multicolumn{2}{|c|}{ Asia Pacífico } & \multicolumn{2}{|c|}{ Norteamérica } & \multicolumn{2}{|c|}{ Resto del mundo } \\
\hline & 1980 & 2014 & 1980 & 2014 & 1980 & 2014 & 1980 & 2014 \\
\hline Destilados ligeros & 4.7 & 4.4 & 2.0 & 10.0 & 8.1 & 10.8 & 2.3 & 4.9 \\
\hline Destilados intermedios & 6.7 & 8.7 & 3.2 & 11.0 & 5.1 & 6.8 & 4.2 & 7.4 \\
\hline Combustóleo & 6.1 & 1.4 & 3.8 & 2.8 & 2.9 & 0.4 & 2.5 & 3.3 \\
\hline Otros & 3.0 & 3.6 & 1.5 & 7.1 & 3.8 & 5.3 & 1.3 & 4.1 \\
\hline Total & 20.5 & 18.1 & 10.5 & 30.9 & 20.0 & 23.3 & 10.2 & 19.8 \\
\hline
\end{tabular}

Fuente: BP (2015).

plantas existentes y el restante $8 \%$ de nueva capacidad, siendo la región asiática la de mayor dinamismo. Las inversiones en la industria de la refinación en el mundo podrían llegar a $102.1 \mathrm{mmbd}$ en el 2020 (IEA, 2015), para ello las empresas enfrentan el reto de evaluar el modelo de operación elegido y su nivel de integración, particularmente en Norteamérica y Europa Occidental (Atkearney, 2012).

En los próximos años, la industria de la refinación internacional continuará incorporando avances tecnológicos, en particular propiciando procesos más eficientes con flexibilidad para producir derivados y ahorradores de energía, un mayor acoplamiento con las plantas petroquímicas y evitando las emisiones gases de efecto invernadero; teniendo como marco de referencia una mejor eficiencia en el consumo energético, destacándose el sector automotriz que espera alcanzar un rendimiento de alrededor de $20 \mathrm{~km} /$ litro hacia el año 2025 (The White House, 2012).

Empero un factor crucial en el futuro de la refinación está asociada a los cambios en las decisiones de inversión derivadas del comportamiento en los precios internacionales del petróleo.

\section{Estados Unidos}

Durante 2014, Estados Unidos consumió un promedio de 19.0 mmbd, continuando con una tendencia decreciente desde inicios de la presente década, sobre todo en petrolíferos ligeros (gasolina y diésel). Los precios de esos productos se determinan por las condiciones de mercado que llevan a las empresas a operar bajo criterios de eficiencia. 
Cuadro 2. Capacidad de destilación primaria mundial

Miles de barriles por día

\begin{tabular}{|c|c|c|c|c|c|c|}
\hline \multirow[t]{2}{*}{ Región/país } & \multicolumn{2}{|c|}{1980} & \multicolumn{2}{|c|}{2014} & \multicolumn{2}{|c|}{$1980-2014$} \\
\hline & No. & Participación & No. & Participación & No. & Participación \\
\hline Estados Unidos & 18620 & $23.5 \%$ & 17791 & $18.4 \%$ & -829 & $-4.5 \%$ \\
\hline Canadá & 2155 & $2.7 \%$ & 1965 & $2.0 \%$ & -189 & $-8.8 \%$ \\
\hline México & 1207 & $1.5 \%$ & 1522 & $1.6 \%$ & 315 & $26.1 \%$ \\
\hline Total Norteamérica & 21982 & $27.8 \%$ & 21278 & $22.0 \%$ & -704 & $-3.2 \%$ \\
\hline Asia Pacífico & 12364 & $15.6 \%$ & 32461 & $33.6 \%$ & 20097 & $162.5 \%$ \\
\hline Europa y Euro Asia & 31911 & $40.3 \%$ & 23724 & $24.6 \%$ & -8187 & $-25.7 \%$ \\
\hline Medio Oriente & 3528 & $4.5 \%$ & 9428 & $9.8 \%$ & 5900 & $167.2 \%$ \\
\hline África & 2073 & $2.6 \%$ & 3553 & $3.7 \%$ & 1480 & $71.4 \%$ \\
\hline Centro y Sudamérica & 7251 & $9.2 \%$ & 6069 & $6.3 \%$ & -1 182 & $-16.3 \%$ \\
\hline Total mundial & 79109 & $100.0 \%$ & 96514 & $100.0 \%$ & 17405 & $22.0 \%$ \\
\hline
\end{tabular}

Fuente: elaborado con datos de BP (2015).

Al cierre de 2014, Estados Unidos contaba con 142 refinerías, lo que representó una reducción de 53\% con relación al año 1982, de las cuales 139 estaban operando y tres no. El número de refinerías se redujo, en virtud de su obsolescencia tecnológica y pérdida de rentabilidad, pero la capacidad de refinación operable se incrementó en $13.4 \%$, lo que se reflejó en un alza en la productividad promedio por refinería en más del doble. ${ }^{4}$ En particular, se incrementó la capacidad de las plantas de coquización -al triple con relación a 1980-, la de desulfuración y la producción de diésel. ${ }^{5}$ Aunque no se han construido grandes refinerías desde la década de los setenta, se han incorporado algunas plantas nuevas de reducida capacidad. ${ }^{6}$

4 Se ha invertido en proyectos de ampliación de capacidad, reemplazo y actualización de plantas, la incorporación de nuevos catalizadores o el mejoramiento de procesos y el impulso de mayor eficiencia energética.

5 El promedio de elaboración de refinados de bajo valor agregado (combustóleo, asfalto y coque de petróleo) fue cercano al $10 \%$ entre enero y octubre de 2015 , el cual se compara con un poco más del 13\% registrado a inicios de los ańos noventa.

6 En 2015 iniciaron su operación Buckeye Partners Corpus Christi, TX (46 mbd), Petromax Refining $(25 \mathrm{mbd})$, Dakota Prairie $(19 \mathrm{mbd})$ y la ampliación de Kinder Morgan Refinery 
La capacidad instalada llegó a $17.8 \mathrm{mmbd}$, correspondiendo en su mayoría a refinerías que procesaron menos de 100 mil barriles diarios (mbd) y una cuarta a capacidades superiores a $250 \mathrm{mbd}$. La estructura de mercado de la refinación en Estados Unidos ha sido resultado de un proceso de fusiones y adquisiciones, ${ }^{7}$ lo que se perfila como un tipo de competencia monopolística. Tan sólo ExxonMobil controla el 10\% de la capacidad total de refinación y las cinco empresas líderes acumulan el 43\% de dicha capacidad (Chesnes, 2015).

La operación de las refinerías ha tendido a mejorar a través del tiempo, logrado optimizar sus tiempos de producción con los de paro por mantenimiento e incrementado su capacidad de utilización, la cual llegó a promediar casi $89 \%$ entre 2004 y 2014. A la estrategia de mejora operativa, se ha aunado el disponer de crudo ligero a menor precio, ${ }^{8}$ pero se preserva la necesidad de importar petróleo pesado para abastecer las refinerías de la costa del Golfo de México, en donde existe un mercado más articulado en crudo y petrolíferos.

Aunque Estados Unidos es un país comprador neto de petróleo que ya puede venderlo al exterior, ${ }^{9}$ la importación de productos derivados del petróleo al interior ha mostrado una tendencia a la baja, pasando de un máximo de $3.5 \mathrm{mmbd}$ en 2005 a $1.9 \mathrm{mmbd}$ en 2014, siendo sus principales países proveedores: Canadá (26.6\%) y Rusia (16.4\%). Por el contrario, las exportaciones de esos productos pasaron de $0.855 \mathrm{mmbd}$ en 1995 a $3.8 \mathrm{mmbd}$ en 2014, siendo el principal destino Centro y Sudamérica (34\%), Europa (22\%), México (16\%), Canadá (8\%), África (4\%) y Medio Oriente (2\%).

Una de las potencialidades del desarrollo de la refinación en Estados Unidos, y del intercambio con el exterior, ha sido la existencia de infraestructura para su transporte. ${ }^{10}$ Algunas refinerías estadounidenses capitalizan el acceder al crudo ligero extraído cerca de sus instalaciones como una ventaja competitiva, sobretodo en el mezclado del petróleo a procesar.

(84 mbd) y en 2008 otra con aumento de capacidad destacó Interline Resources Refinery (4 mbd), así como otros proyectos (EIA, 2016).

7 Hacia fines de la década de los noventa, 40 compañías contaban con refinerías, pero a fines de 2013 se habían reducido a un poco más de la mitad (EIA, 2013). La calidad del crudo procesado por las refinerías promedió $30.4^{\circ}$ API en la década pasada y desde 2010 aumentó a $31.8^{\circ}$ API al cierre de 2014, empero su contenido de azufre se elevó, lo que ha obligado a continuar importando crudo pesado.

9 Estados Unidos levantó la prohibición de exportar crudo en diciembre de 2015, luego de más de 40 años de que se mantuvo la disposición por parte del Energy Policy and Conservation Act.

Estados Unidos cuenta con un sistema complejo de ductos seguro, rápido, eficiente, con una extensión de 307 mil kilómetros y un robusto sistema de transporte ferroviario, particularmente en las refinerías del Este, que se complementa con el autotransporte. 


\section{Canadá}

En Canadá, la industria de la refinación es un importante contribuyente de la economía, pues aportó alrededor del 4\% del Producto Interno Bruto (РIB) en 2013 y empleó más de 18 mil personas con salarios competitivos (Canadian Fuels Association, 2014). Desde 1970, el país ha enfrentado un proceso de reestructuración, que le ha llevado a cerrar más de 20 refinerías, ampliado y actualizado otras, pero no ha construido una nueva desde 1984. Al cierre de 2014, contaba con 15 refinerías con una capacidad instalada de 1.9 mmbd. Algunas plantas tienen una antigüedad de más tres décadas y producen un elevado porcentaje de combustóleo (20\% del total de los productos elaborados), lo que les lleva a registrar baja eficiencia. Está en proceso de construcción una refinería en Sturgeon County en Edmonton, ${ }^{11}$ que se espera opere a partir de 2017, siendo una de sus características que capturará Bióxido de Carbono $\left(\mathrm{CO}_{2}\right)$, que se inyectará en campos petroleros.

El grueso de la oferta de petrolíferos es realizado por tres compañías (Shell, PetroCanada, y Imperial Oil) y un puñado de empresas regionales (Irving Oil, Ultramar, Suncor Energy, Federated Co-op, Husky y Chevron), la mayoría de propiedad canadiense y estadounidense. Cuenta con plantas que usan petróleo como insumo para elaborar asfáltenos, plantas petroquímicas y las denominadas upgraders, que además de transformar crudo pesado en ligero, producen diésel. Con pequeñas excepciones, los productos terminados son distribuidos por las propias compañías.

Canadá es un país exportador neto de petróleo, ${ }^{12}$ y sus importaciones de petrolíferos representan alrededor del $12 \%$ de su consumo, en su mayoría de Estados Unidos (Natural Resources Canada, 2014), sobre todo por razones de logística, pues dispone de excedentes en el Este y faltantes en el Oeste del país. ${ }^{13}$

El petróleo procesado corresponde en buena parte a crudo ligero, empero también al sintético obtenido de las arenas bituminosas, el cual es vulnerable

11

La inversión en la refinería de Sturgeon en una primera fase será de alrededor de 11 mil millones de dólares ( $\mathrm{mmmd}$ ) y procesará $79 \mathrm{mbd}$ de bitumen diluido y producirá productos de ultra bajo azufre, entre otros productos.

12

13

exportaciones netas de petróleo crudo de Canadá sumaron $2.4 \mathrm{mmbd}$ en 2014: del total de las exportaciones casi la mitad correspondió a aceite sintético y de bitumen. Del total producido de derivados de petróleo más de una cuarta parte fue exportada, principalmente a Estados Unidos.

La industria de refinación canadiense cuenta con amplia disponibilidad de crudo e infraestructura de proceso en la costa Este, pero tiene que importar en la Oeste -además de enfrentar la competencia estadounidense en esa región-. 
a la baja en los precios del petróleo, pues afronta costos de producción de al menos 40 dólares por barril. $\mathrm{Al}$ ser uno de los principales países productores de automóviles en el mundo, la industria de la refinación canadiense ha estado centrada en la calidad de los combustibles, en particular en la reducción en los niveles de azufre en la gasolina (90\%) y en el diésel (97\%). También se están empleando energías alternativas, pues las gasolinas contienen alrededor del 5\% y el diésel el 2\% de biocombustibles (Canadian Fuels Association, 2015).

\section{EL DESEMPEÑO DE LA REFINACIÓN EN MÉXICO}

La industria de la refinación en México ha sido pieza fundamental en el crecimiento de la economía, pues ha suministrado de manera oportuna los combustibles e insumos, principalmente al sector transporte. Por su desarrollo alcanzado, Pemex se ubicó dentro de las primeras 15 compañías con capacidad de refinación en el mundo registradas en 2014. La subsidiaria de Pemex que llevaba la operación de la refinación era Pemex Refinación (PR), pero a partir de noviembre de 2015 se integró a Pemex Transformación.

Luego de su impulso hasta la época del boom petrolero, que la llevó a lograr avances tecnológicos a través del Instituto Mexicano del Petróleo transcendiendo fronteras con productos como el proceso DEMEx, la refinación en México enfrentó la falta de recursos de inversión para su actualización y crecimiento desde la década de los ochenta, sobre todo desde que la política petrolera se centró en el desarrollo del macro yacimiento Cantarell.

El promedio medio anual de inversión ascendió a 0.71 miles de millones de dólares (mmmd) entre 1991 y 1999. Ello derivó en insuficiente mantenimiento, limitación para incorporar tecnología, mejoras operativas y en no aumentar la capacidad instalada. Además, se cerraron las unidades de Azcapotzalco, Poza Rica y Reynosa a inicios de los ańos noventa.

El programa de reconfiguración del Sistema Nacional de Refinación (SNR) fue autorizado a fines de los años noventa y contempló construir nuevas plantas de proceso, su ampliación y modernización. Los montos de inversión se elevaron a cerca de $2 \mathrm{mmmd}$ en promedio anual entre 2000 y 2001, para desarrollar trabajos en las refinerías de Cadereyta y Madero y luego reducirse a $0.66 \mathrm{mmmd}$ entre 2002 y 2005 . Fue a partir de 2006 cuando de nuevo se le inyectaron recursos, llegando a promediar $1.9 \mathrm{mmmd}$ por año hasta el 2014, resaltando los proyectos de Calidad de Combustibles y la reconfiguración de Minatitlán (véase cuadro 3). Así, las refinerías de Cadereyta, Madero y Minatitlán culminaron su reconfiguración y aumentaron el volumen procesado de 
petróleo crudo pesado en $15.0,11.0$ y $122.9 \%$, respectivamente, y la producción de combustóleo disminuyó en 48.6, 64.9 y 69.4\% (ASF, 2014).

Al cierre de 2014, Pemex contaba con seis unidades en el SNR con una capacidad instalada de procesamiento de $1.6 \mathrm{mmbd}$, sólo $2.8 \%$ por arriba de la que contaba en el año 2000, pero 5\% debajo de la registrada en $1990 .{ }^{14}$ Además mantenía el 50\% de la participación accionaria de Deer Park, que es operada por Royal Dutch Shell, y que controla la otra mitad de la propiedad.

La estrategia del manejo de la refinación, que ha implicado no construir una nueva unidad desde 1979, ha llevado a colocar el crudo extraído en el exterior, en lugar de procesarlo, siendo la costa del Golfo estadounidense uno de sus principales destinos y donde se adquiere una parte importante de los petrolíferos importados.

En general, el panorama mostrado de la refinación en el país denota una situación compleja, derivado de su dependencia de las finanzas públicas ${ }^{15} \mathrm{y}$ de un conjunto de factores ligados a su desarrollo a lo largo de toda su cadena de valor a través del tiempo, siendo los más relevantes:

- Los tipos de petróleo crudo suministrado por Pemex Exploración y Producción (PEP) no cumplen con las consideraciones técnicas requeridas por la configuración de las refinerías, que fueron diseñadas para procesar crudos ligeros, lo que deriva en dificultades para alimentarlas con la mezcla de crudo adecuada. ${ }^{16}$ A lo que se ańade que los precios del crudo adquirido a Pemex pep son a referencia internacional, lo que limita las ventajas relativas que puede tener una empresa integrada.

- En la operación de las refinerías existen problemas que limitan su rentabilidad, tales como: bajo nivel de utilización de su capacidad instalada, debido a los paros no programados y problemas técnicos, ${ }^{17}$ que contrastó

14

Se ha incrementado la capacidad de las plantas de hidrodesulfuración, alquilación e isomerización y coquización, pero reducido las de destilación al vacío, desintegración catalítica y de reducción de viscosidad.

El gasto de inversión en el área de refinación se ha reducido en innumerables ocasiones desde los años ochenta, uno de los más reciente sucedió con los proyectos contratados durante 2014, y que serían construidos en plazos de entre 3 y 3.5 ańos. Estos fueron diferidos en febrero de 2015, con el ajuste de $11.5 \%$ al presupuesto de Pemex.

Los problemas para contar con una mezcla adecuada que alimente a las refinerías detonó en la necesidad de plantear el intercambio de crudo pesado por ligero con Estados Unidos en 2015.

Entre los principales problemas de paros no programados enfrentados, se encuentran los altos niveles de inventarios de combustóleos, problemas en el suministro de crudo, fallas en la energía eléctrica, amén de los accidentes ocurridos en algunas plantas, como el sucedido en Tula con la planta reductora de viscosidad en 2011. 
Cuadro 3. Inversiones en refinación, 2006-2014

Millones de dólares

\begin{tabular}{lrrrrrrrrr}
\hline Proyecto & 2006 & 2007 & 2008 & 2009 & 2010 & 2011 & 2012 & 2013 & 2014 \\
\hline Calidad de Combustibles & - & - & - & 32 & 268 & 470 & 504 & 214 & 531 \\
$\begin{array}{l}\text { Conversión Residual } \\
\text { Salamanca }\end{array}$ & - & - & - & 8 & 5 & 6 & 12 & 70 & 89 \\
Reconfiguración Tula & - & - & - & - & - & - & - & - & 73 \\
Nueva Refinería Tula & - & - & - & 3 & 11 & 4 & 34 & 398 & 32 \\
Ducto Tuxpan y TAR & - & - & - & 48 & 67 & 55 & 46 & 20 & 19 \\
Reconfiguración Minatitlán & 764 & 847 & 639 & 382 & 375 & 204 & 412 & - & - \\
Otros & 627 & 615 & 913 & 899 & 1106 & 1060 & 1216 & 1577 & 1958 \\
Total & 1391 & 1462 & 1552 & 1371 & 1832 & 1798 & 2225 & 2278 & 2702 \\
\hline
\end{tabular}

Nota: TAR. Terminal de Almacenamiento y Reparto.

Fuente: Pemex F-20.

con el de los países vecinos de Norteamérica y con otras naciones asiáticas (véase gráfica 1). Esto ha llevado a disminuir el volumen de crudo procesado en el SNR, y por ende, el de los productos refinados; registran elevados índices de consumo de energía, ${ }^{18}$ que se reducirán parcialmente con la entrada de los proyectos de cogeneración en las refinería de Salina Cruz, Tula y Cadereyta; ${ }^{19}$ experimentan falta de actualización tecnológica de los equipos y procesos utilizados, que limita su capacidad para procesar calidades de crudo con alto contenido de azufre y metales, como el que se dispone en el país; registran limitados rendimientos de productos de alto valor de mercado y una producción excedente de combustóleo, que no puede ser colocado en el mercado nacional por problemas de calidad y por la tendencia a emplear gas natural en la generación de electricidad en vez de ese combustible.

Las seis refinerías mexicanas utilizan 43\% más energía que el estándar internacional de la industria de la refinación (IMCO, 2013).

19 Los proyectos en desarrollo en las refinerías de Salina Cruz, Tula y Cadereyta contarán con una capacidad de 1683 megawatts/hora y de vapor de 3050 toneladas hora, y se proyecta una inversión junto con el proyecto del Complejo Procesador de Gas de Cactus, Chiapas, de aproximadamente $3 \mathrm{mmmd}$, de las cuales una mayor parte provendrá de la iniciativa privada (Pemex, 2015a). 
Gráfica 1. Utilización de la capacidad instalada en naciones seleccionadas

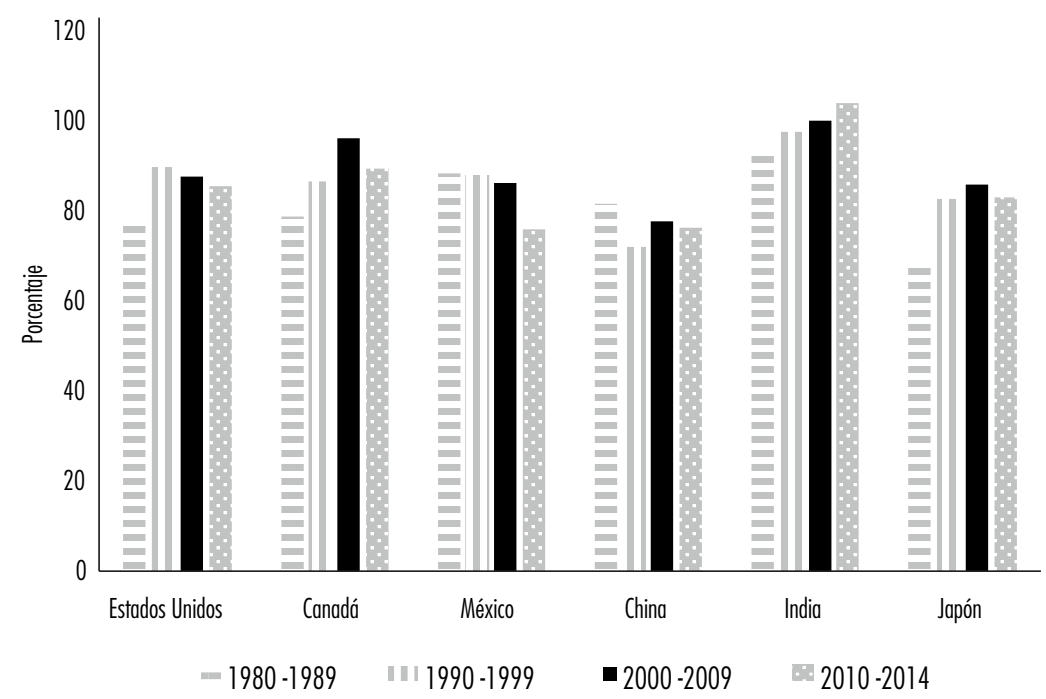

Fuente: BP.

- A pesar del programa de combustibles limpios, PR no ha logrado cumplir con las metas determinadas en el NOM $086,{ }^{20}$ debido a que no cuenta con los recursos financieros para disponer de la infraestructura para ello, lo cual redunda en una pérdida de competitividad de los combustibles elaborados en el mercado de Norteamérica. A lo anterior se le añaden retos que el gobierno ha comprometido en materia de cambio climático ${ }^{21}$ y que afronta con el denominado Plan de Acción Climática.

- A nivel gerencial, se presentan dificultades en la implementación de los programas y las estrategias instrumentadas que propicien una mejora operativa, tal como aconteció con el Programa de Mejoramiento del Desempeño Operativo (PMDO) después de la reforma energética de año $2008 ;^{22}$ se

De acuerdo a la Nom 086, Pemex debió haber suministrado gasolina magna de 30 promedio y 80 máximo ppm de azufre y diésel de 15 máximo partes por millón de azufre desde enero de 2009 en todo el país y no lo ha hecho.

21 En el marco de la Cumbre Mundial sobre Cambio Climático (COP21) realizada en París, México se comprometió a reducir la emisión de gases de efecto invernadero, realizando inversiones en la industria de la refinación.

22 En 2010, se puso en marcha el Programa de Mejoramiento del Desempeño Operativo (MDo) en las refinerías de Madero y Salina Cruz, y en 2011, en Tula, Cadereyta, Salamanca y Minatitlán, pero con resultados poco satisfactorios. Entre 2010 y 2013, Pemex Refinación reportó un aumento promedio anual real de $3.9 \%$ en los gastos de transporte y distribución, de $0.4 \%$ en los de 
cuenta con problemas de burocracia que hacen lenta la toma de decisiones, tanto por la estructura organizacional que se fue estructurando a través de los ańos, como del exceso de personal que labora en $\mathrm{PR}^{23}$ en comparación con otras compañías internacionales del mismo giro, lo que redunda en una baja productividad de ventas por empleado. En buena parte esta última situación es atribuible al poder de negociación del Sindicato de Trabajadores Petroleros de la República Mexicana, que no se limita a la representación laboral sino que abarca además los intereses particulares que mantiene en las actividades de $\mathrm{PR}^{24}$

- Incapacidad de ejecución de las inversiones de la PR, pues no se ha logrado capitalizar los planes de la empresa ni en tiempo ni en forma en la mayoría de los casos. Ejemplo de ello fue el diferimiento en los proyectos de la reconfiguración de las refinerías de Cadereyta y Minatitlán, lo que ha detonado en incurrir en gastos no productivos. Pero el caso más relevante fue el proyecto fallido de la nueva refinería de Tula, ${ }^{25}$ en la que se erogaron un poco más de 480 millones de dólares, y se argumentó, que muchos de los trabajos se retomarían en la refinería que opera en ese lugar.

- Enfrenta insuficiente capacidad de almacenamiento de crudos en refinerías y de destilados en sus Terminales de Almacenamiento y Reparto, que origina problemas de saturación en algunas líneas de transporte, ${ }^{26}$ principalmente en el centro del país cuando acontecen fallas o eventos imprevistos, por ejemplo, los robos de combustibles o los accidentes por fugas de combustible. Ello convive con el uso no óptimo de los ductos e infraestructura de poliductos, su rezago tecnológico y edad promedio de más de 25 años.

administración, que contrastó con una reducción en los costos de venta de $3.9 \%$, el cual estuvo más asociado a la baja en $4.1 \%$ en el precio del petróleo.

Pemex Refinación contaba con 47576 empleados al cierre de 2014, el 31\% de Pemex en su conjunto, luego que en 2004 redujo su plantilla a 44899 personas desde un nivel de 48867 que registró en 1994.

24 Rodrigo Olvera Briseño del Centro de Reflexión y Acción Laboral (Cereal), dice que "es bastante conocido que los mismos administradores de refinerías o de centros de trabajo crean compañías outsourcing que son de ellos mismos y se adjudican los contratos de trabajo que tienen que hacer los trabajadores de Pemex" (Revista Contralinea, 2013).

La propuesta aprobada por el Congreso sobre la nueva refinería, que entraría en operación en el año 2015 con una capacidad de 300 mil barriles diarios, demostraba que se podría lograr una ganancia anual de $3 \mathrm{mmmd}$ al año, sobre un costo estimado en $9 \mathrm{mmmd}$ (González, 2013).

México cuenta con sólo $5213 \mathrm{~km}$ de oleoductos y $8946 \mathrm{~km}$ de poliductos, en su mayor parte distribuidos en la parte centro-norte y Golfo de México. El transporte de petrolíferos se realiza por ductos $(66 \%)$, buque tanque (15\%), por tren (5\%) y el resto por autotransporte. En particular, el transporte desde las Terminales de Almacenamiento y Reparto para su distribución a los puntos de expendio al público se realiza mediante autotanques (Secretaría de Energía, 2016). 
- Un serio problema enfrentado por PR es la falta de detección oportuna de las tomas clandestinas ${ }^{27}$ y el crecimiento del mercado ilícito de combustibles. ${ }^{28}$ En el primer caso, el problema ha ido acompañado de frecuentes fugas y derrames, algunos de gran alcance como el ocurrido en San Martín Texmelucan, Puebla, en 2010, que se anexan a los ocurridos durante la operación diaria de la empresa.

- Pese a las inversiones concretadas en el proyecto de Combustibles Limpios, queda pendiente el cumplir con la norma de reducir el contenido de azufre en las gasolinas y en el diésel, pues sólo se ha logrado atender los requerimientos para algunas de las principales zonas metropolitanas del país.

- Una de las demandas por atender en la refinación en México es su rezago y dependencia tecnológica, pues la IDT se dejó de impulsar desde mediados de los años ochenta. Ni Pemex ni el Imp le destinaron recursos financieros suficientes y en forma adecuada para su impulso, y menos en un ambiente en donde la creación de infraestructura estaba restringida, lo que a su vez originó, que no se hayan formado los investigadores que demandan los retos tecnológicos actuales.

- El mecanismo de distribución de gasolinas y diésel de PR ha aumentado a través del tiempo ${ }^{29}$ y mejorado con la oferta de servicios complementarios (tiendas de conveniencia o servicios auxiliares), empero enfrenta problemas de imagen, pues las estaciones de servicio no suministran "litros de a litro" y en algunos caso expenden productos obtenidos del mercado ilícito o se ubican en lugares no adecuados para su operación, por ejemplo, área de hospitales o de concentración social.

- La limitada capacidad de influencia de los consumidores redunda en la oferta de productos con problemas de calidad. Entre 2004 y 2013, la satisfacción de la demanda interna de los principales petrolíferos (gasolinas, diésel y turbosina) cubierta con producción nacional descendió de 82.3 a 63\% (ASF, 2014).

Durante 2014, se identificaron y clausuraron 4125 tomas clandestinas (TC), cifra $43.7 \%$ mayor a las 2871 detectadas en 2013. El estado de Tamaulipas fue el que mayores casos observó (641), lo que representó $16 \%$ del total nacional de los ductos de PR. Le siguieron Guanajuato con 524 TC (13\%), Sinaloa con 519 тc (13\%) y Jalisco con 359 тc (9\%) (Pemex, 2015 b).

De los más de 800 mbd de combustible que se producen en México, 27 mbd se pierden por delitos como el robo (Mundo Ejecutivo Express, 2015). quicias (10 783) y las operadas por PR (47). Esto es más del triple del nivel registrado en 1990 y del doble en el año 2000. 
- La refinación en México no ha sido un negocio rentable, pues pese a que los ingresos de PR han aumentado, acumula pérdidas consecutivas desde el año 1994, lo que se ha traducido en un patrimonio negativo cercano a los $20 \mathrm{mmmd}$ al cierre de 2014, atípico en la industria (véase cuadro 4). El cúmulo de dificultades se ha agudizado porque PR -y Pemex en su conjuntoregistran alto apalancamiento, problemas liquidez, y baja productividad. ${ }^{30}$

Ante las restricciones presupuestales que es probable enfrente la petrolera, tanto por la situación financiera del sector público, como de la posibilidad de precios bajos del petróleo, al menos hasta finales de la presente década, el relanzamiento de la refinación estatal parece complicado sobre todo considerando los proyectos oficiales planeados.

Cuadro 4. Inversiones en Pemex Refinación, 2006-2014

Miles de barriles por día

\begin{tabular}{|c|c|c|c|c|}
\hline Concepto & 1990-1999 & $2000-2009$ & $2010-2014$ & 2014 \\
\hline \multicolumn{5}{|l|}{ Capacidad de refinación } \\
\hline Destilación atmostérica & 1538 & 1544 & 1642 & 1602 \\
\hline Destilación al vacío & 751 & 764 & 804 & 768 \\
\hline \multicolumn{5}{|l|}{ Desintegración catalítica } \\
\hline y térmica & 340 & 386 & 414 & 423 \\
\hline Reducción de viscosidad & 112 & 121 & 91 & 91 \\
\hline Reformación de naftas & 190 & 286 & 279 & 279 \\
\hline Hidrodesulfuración & 644 & 926 & 1056 & 1068 \\
\hline Fraccionamiento de líquidos & 71 & & & - \\
\hline Alquilación e isomerización & & 125 & 147 & 154 \\
\hline Coquizadora & & 88 & 145 & 156 \\
\hline Proceso de petróleo crudo y líquidos en refinería & 1292 & 1271 & 1186 & 1155 \\
\hline
\end{tabular}

30 Desde el 2008 y hasta el 2014, PR reportó un patrimonio negativo, que le llevó a registrar un apalancamiento -pasivos totales a activos totales- de 1.5 veces en ese último año. Además, entre 2011-2014 presentó un indicador de liquidez negativo. Esto se conjuga con un nivel de ventas por empleado muy por debajo de los estándares internacionales (véase cuadro 4). 


\begin{tabular}{|c|c|c|c|c|}
\hline Concepto & 1990-1999 & $2000-2009$ & $2010-2014$ & 2014 \\
\hline Cadereyta & 161 & 198 & 181 & 181 \\
\hline Madero & 147 & 139 & 123 & 111 \\
\hline Minatitlán & 185 & 169 & 166 & 168 \\
\hline Salamanca & 171 & 191 & 180 & 171 \\
\hline Salina Cruz & 281 & 290 & 272 & 270 \\
\hline Tula & 254 & 284 & 264 & 255 \\
\hline \% de crudo pesado procesado & $49 \%$ & $38 \%$ & $26 \%$ & $34 \%$ \\
\hline Elaboración de productos petroliferos & 1510 & 1517 & 1408 & 1385 \\
\hline$\%$ de gasolina & $27 \%$ & $29 \%$ & $30 \%$ & $30 \%$ \\
\hline$\%$ de diésel & $18 \%$ & $20 \%$ & $21 \%$ & $21 \%$ \\
\hline$\%$ de querosina & $5 \%$ & $4 \%$ & $4 \%$ & $4 \%$ \\
\hline Volumen de las ventas internas petroliferos & 1498 & 1746 & 1777 & 1709 \\
\hline \% de gasolina diésel y querosina & $52 \%$ & $59 \%$ & $70 \%$ & $72 \%$ \\
\hline Volumen de exportación de petrolíferos & 116 & 169 & 182 & 201 \\
\hline$\%$ de gasolina diésel y querosina & $49 \%$ & $54 \%$ & $41 \%$ & $34 \%$ \\
\hline Volumen de importación de petrolíferos & 206 & 365 & 644 & 641 \\
\hline \% de gasolina diésel y querosina & $46 \%$ & $54 \%$ & $79 \%$ & $80 \%$ \\
\hline Número de empleados Pemex Refinación & 47746 & 45922 & 46801 & 47576 \\
\hline \% sobre total de Pemex & $35 \%$ & $33 \%$ & $31 \%$ & $31 \%$ \\
\hline
\end{tabular}

Fuente: elaborado con datos del Sistema de Información Energética y Pemex. 
Gráfica 2. Resultados Netos y Ventas de Pemex Refinación.

Millones de dólares

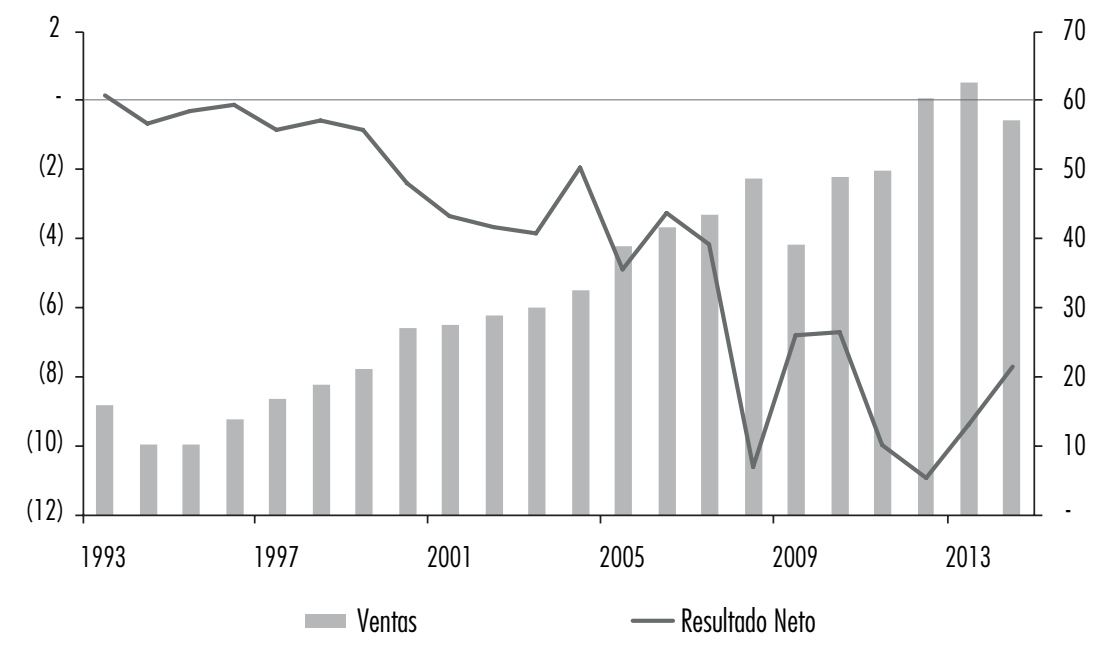

Fuente: Pemex F-20.

\section{PERSPECTIVAS DE LA REFINACIÓN EN MÉXICO}

El consumo de productos derivados en México ha aumentado como resultado del incremento en la actividad económica, pero también por la decisión política de no impulsar otras alternativas de transporte, como el ferrocarril o el transporte público. En otras ocasiones los menores precios de las gasolinas y el diésel, respecto de sus referencias internacionales, fueron factor de impulso al consumo, particularmente hasta antes de los años ochenta (Romo, 2011).

El desempeño de la refinación en Pemex ha originado que el país se haya constituido en un importador neto de petrolíferos y a partir de 2015 en deficitario en la balanza comercial petrolera, siendo la gasolina el principal producto adquirido del exterior (véase gráfica 2) y solo exportador neto de combustóleo. De hecho, casi la mitad del consumo nacional aparente de gasolina tiene que importarse, es decir, existe un mercado cautivo por abastecer que en el año 2014 fue de un poco más de $350 \mathrm{mbd}$.

Estimaciones oficiales (Secretaría de Energía, 2014), señalan que en el año 2028 se demandarán en el país cerca de 2 mmbd de petróleo crudo equiva- 
lente de petrolíferos, 38\% más que el consumo de $2013 .{ }^{31}$ Las gasolinas serían las de mayor demanda, seguida del diésel, como resultado de su uso intensivo en el autotransporte.

Con la aprobación de la reforma energética de diciembre de 2013, el gobierno estableció las condiciones para que las empresas públicas o privadas traten y refinen petróleo en el país, sujetos a un régimen legal ${ }^{32}$ y fiscal, que contiene algunos espacios para impulsar la participación de las compañías privadas, como la deducción inmediata de inversiones.

En un mercado que será de competencia a partir de 2018, y en el que el consumidor no mantiene una capacidad de influencia, existe la potencialidad para ofertar productos petrolíferos que se elaboren en el país, y en el caso de los ligeros, ofrecerse en mezclas con combustibles de origen renovable, como el etanol.

México es exportador neto de petróleo crudo, por lo que dispone de volúmenes para su procesamiento. El reto será que las empresas privadas que lo exploten tengan la capacidad de procesarlo, aunque no todas las compañías ganadoras en la Ronda Uno se dedican a las actividades de downstream.

Atender la demanda esperada de productos refinados, implicaría llevar a cabo alguna de las siguientes acciones, o la combinación de ellas:

a) Que se relancen las inversiones en Pemex, tanto para ampliar la capacidad de refinación o crear nueva, lo que resulta complicado dadas las restricciones financieras gubernamentales, que se conjuga con la falta de voluntad política. ${ }^{33}$ De hecho, primero se debe atender el rezago en los proyectos de reconfiguración de las tres refinerías (Tula, Salamanca y Salina Cruz),

Hacia el 2028, el sector transporte será el que mayor volumen de petrolíferos demandará $(51.4 \%$ del consumo total), seguido del industrial (17\% del total) y del eléctrico que observará menor crecimiento (31.2\% del total), luego que en 2013, la participación en el total en cada caso fue de 46.8, 13.8 y $37.2 \%$, respectivamente (Secretaría de Energía, 2014).

La Secretaría de Energía está facultada para otorgar permisos para que cualquier compañía invierta en refinación, así como para la exportación e importación de los petrolíferos. Destaca el tratamiento al diésel y a la gasolina que podrán importarse por privados a partir de abril de 2016. En tanto, la Comisión Reguladora de Energía hace lo propio con los permisos para el transporte, el almacenamiento, la distribución y el expendio al público de hidrocarburos y petrolíferos. Lo anterior, con independencia de la supervisión y vigilancia del cumplimiento normativo aplicable en cada una de esas instituciones.

Un ejemplo de una política pública de aliento a la refinación ha sido el caso de la India, en donde se empleó el Sistema Sectorial de Innovación consistente en una participación activa del gobierno en su regulación e impulso, la instrumentación de estrategias de las empresas en la industria y la adopción de estándares legales ambientales internacionales (Iyer, 2015). 
canalizar adicionales recursos al Proyecto de los Combustibles Limpios y a la atención de los citados compromisos gubernamentales en materia ambiental a nivel internacional.

b) Impulsar las coinversiones entre Pemex y la iniciativa privada, en las que la capacidad de negociación de la petrolera estatal estaría basada en la disponibilidad de infraestructura por utilizar. Pero también existe la alternativa de la venta de dicha infraestructura de refinación a las empresas privadas.

c) Que las empresas privadas nacionales constituyan la infraestructura nueva requerida para elevar la oferta de los petrolíferos.

d) Adquirir los faltantes del exterior a través de las importaciones, para lo cual se requiere construir la infraestructura de transporte para mejorar la conectividad de las refinerías y reducir los problemas de saturación, así como crear las condiciones para flexibilizar las operaciones en las que puedan participar las compañías privadas. El reto será que dicho sector construya la infraestructura citada, que no realizó de manera óptima en el caso de los gasoductos, en los que podían invertir desde mediados de la década de los noventa.

Al igual que en el escenario internacional, la determinación de invertir en refinación por las compañías particulares estará sujeta a acceder a atractivas condiciones de rentabilidad, en las que podrían ser relevantes los estímulos gubernamentales, la volatilidad en los precios del crudo y las condiciones de su formación en el mercado de los petrolíferos, ${ }^{34}$ y por supuesto el desempeño operativo de las compañías.

En suma, el desarrollo de la industria de la refinación mexicana estará sujeto al rol de la inversión de particulares para su relanzamiento, quienes ya han anunciado algunos proyectos en transporte, distribución, almacenamiento, expendio y servicios de autoconsumo de petrolíferos, así como la probable construcción de nuevas refinerías. ${ }^{35}$ Pemex jugará un rol también relevante en la industria, porque será el comodín en la oferta de los derivados del petróleo, pues tendrá que copar espacios que las empresas privadas no atenderán. Por lo anterior, es deseable acelerar sus estrategias de reconversión, pero también

\footnotetext{
34

Por ejemplo en naciones que operan bajo principio de libre mercado, se ha observado un comportamiento asimétrico entre los precios de la gasolina al menudeo y los de mayoreo, lo que tiene implicaciones sobre los márgenes de ganancia al menudeo (Brewera et al., 2014).

35 A mediados de 2015, un consorcio internacional de empresas de México y de Estados Unidos anunció que presentaría un permiso para la construcción de seis nuevas refinerías con costo aproximado de 6 mil md y una producción de petrolíferos cercana a los $360 \mathrm{mil}$ bd.
} 
acceder a apoyos financieros, plena autonomía en la toma de decisiones ${ }^{36}$ y un cambio en la cultura organizacional.

\section{CONCLUSIONES}

La refinación es un negocio complejo e intensivo en capital con retornos de inversión de largo plazo, que demanda de eficiencia, tecnología, buena gestión y acoplarse a las normas ambientales para elaborar productos limpios, en donde el insumo principal, el petróleo crudo, muestra comportamientos volátiles de precio y condiciones particulares de disponibilidad para su tratamiento.

A pesar del cierre de unidades en las naciones desarrolladas, la industria de la refinación mundial registra una capacidad instalada excedente, derivada principalmente de las inversiones en los años pasados en la región Asia-Pacífico y en el Medio Oriente, y de su actualización en otras naciones. Ello en un mercado en donde el consumo de productos petrolíferos se ha reducido en las naciones más desarrolladas y aumentado en el resto de naciones, pero que se perfila hacia un mayor crecimiento en los ańos siguientes, particularmente por la dinámica del sector transporte.

Estados Unidos y Canadá han elevado su capacidad de refinación debido a la actualización de sus plantas, no obstante, han cerrado otras no rentables. Su estructura de mercado es del tipo competencia monopolística. El primer país, registran una balanza superavitaria en petrolíferos, y el segundo una muy cercana al equilibrio, pero importan y exportan por cuestiones de logística. Operan fundamentalmente bajo criterios de libre mercado y con reducidos crecimiento en su consumo. Incluso con el déficit que México registra, la región presenta un superávit, que bien puede ser utilizado en el caso de mayores compras mexicanas, sobre todo porque se encuentra en la costa del Golfo de México en donde existe infraestructura para su transporte.

En el caso de Pemex, la paraestatal ha logrado abastecer oportunamente el consumo nacional de petrolíferos con producción interna e importaciones. No obstante, acumula un conjunto de problemas estructurales a lo largo de toda su cadena de valor, que la hacen no rentable y la mantienen con problemas de liquidez y un elevado apalancamiento. Su desempeño operativo del gobierno. Siendo su presidente el secretario de Energía, quien es uno de los promotores de la apertura del sector energético, con el agravante de quien decide los cambios corporativos es el gobierno federal dando un toque político al manejo de la empresa. 
ha sido poco eficiente y se ha visto marcado por aportaciones limitadas de recursos por parte de los gobiernos en turno, que le han impedido impulsar sus inversiones, mantenimiento y actualización de plantas o incluso la construcción de nuevas unidades. Ello en un contexto en el que la prioridad en la política petrolera desde los años ochenta, se ha concentrado en la explotación de los hidrocarburos y no en las actividades que le añaden valor al crudo extraído.

El consumo de derivados de petróleo en el país continuará creciendo en los próximos años, especialmente en el caso de los productos ligeros, en un contexto de producción excedente de petróleo crudo por lo menos hasta mediados de la próxima década. Con la aprobación de la reforma energética de 2013, se deja que la iniciativa privada sea el actor principal para impulsar la industria de la refinación nacional, empero para evitar problemas de desabasto, Pemex tendrá que operar los mercados en los que las compañías privadas no lo hagan. Dicha participación, seguirá sujeta a las restricciones de autonomía de gestión en decisiones estratégicas y a limitaciones presupuestales por lo menos en lo que resta de la presente década, así como a la estrategia del gobierno por impulsar espacios para otros jugadores a fin de dar viabilidad a la reforma energética. Lo anterior deja a la petrolera estatal en el camino de asociarse o vender activos, y por supuesto, perder influencia y participación en un mercado en el que era jugador único. 


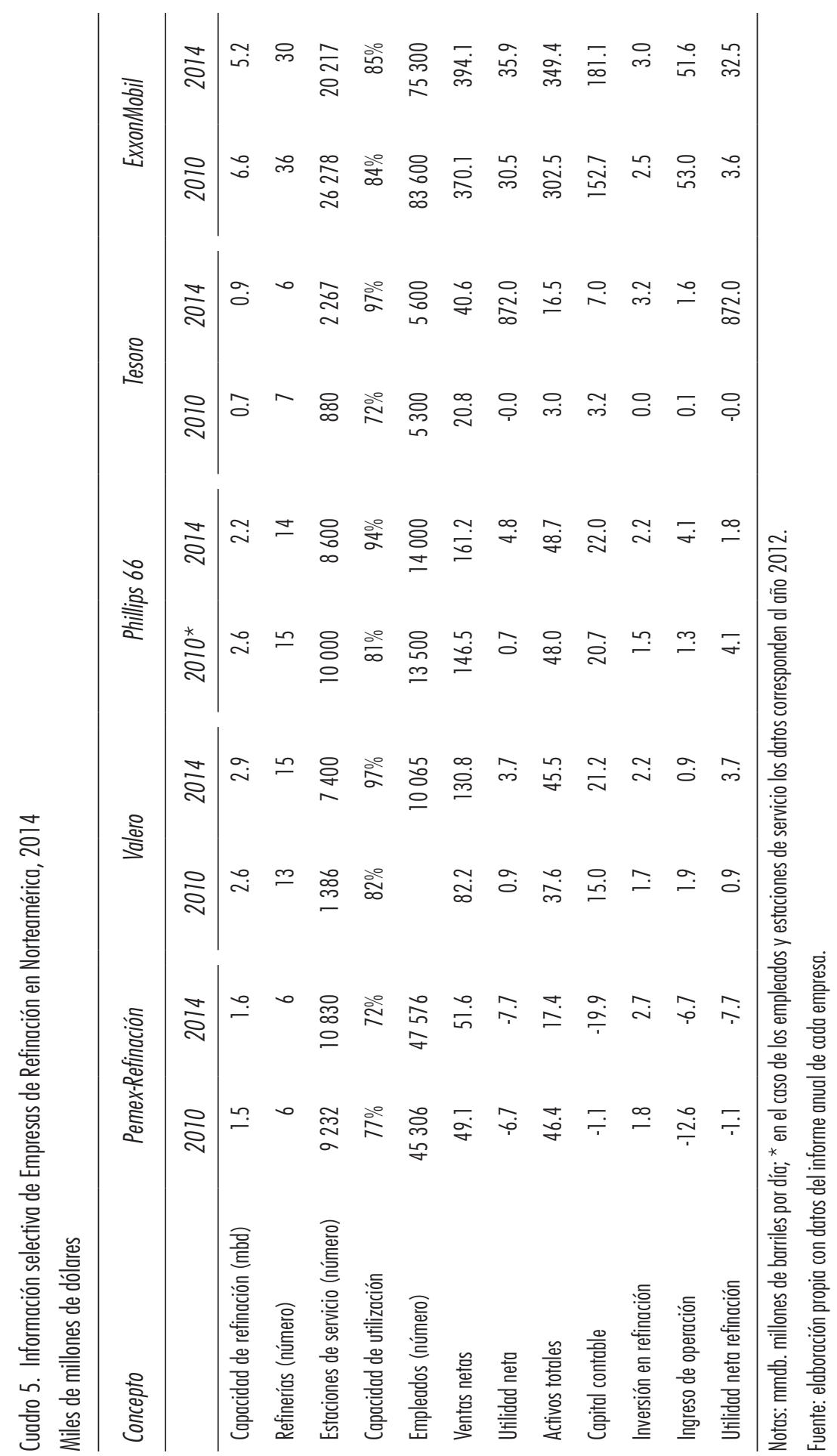




\section{BIBLIOGRAFÍA}

Atkearney (2012), Refining 2021: Who will be in The Game? (consultado el 12 de octubre de 2015) disponible en <https:/www.atkearney.com/paper/-/ asset_publisher/dVxv4Hz2h8bS/content/refining-2021-who-will-be-inthe-game-/10192\#sthash.QU1Ub55V.dpuf>

Auditoría Superior de la Federación (ASF) (2014), Informes de las Auditorías de Desempeño: Refinación de Petróleo Crudo, México (consultado el 23 de octubre de 2015) disponible en <http://www.asf.gob.mx/Trans/Informes/IR2013i/Paginas/Master.htm>

Brewera, Jedidiah, David M. Nelsonb and George Overstreet (2014), "The Economic Significance of Gasoline Wholesale Price Volatility to Retailers", Energy Economics, vol. 43, pp. 274-283.

Canadian Fuels Association (2014), "Petroleum Canada's Fuel, FUEL 2014", Sector Review.

(2015), “Petroleum Canada's Fuel, FUEL 2015”, Sector Review.

Chesnes, Matthew (2015), "The Impact of Outages on Prices and Investment in the U.S. Oil Refining Industry”, Energy Economics, vol. 50, pp. 324336.

Congressional Research Service (2015), "Mexico's Oil and Gas Sector: Background, Reform Efforts, and Implications for the United Status", USA, January, 27.

Energy Information Administration (EIA) (2013), Genealogy of Major U.S. Refineries (consultado el 18 de diciembre de 2015) disponible en <http:// www.eia.gov/finance/genealogy/>

(2016) (consultado el día 30 de enero de 2016) disponible en <https:// www.eia.gov/tools/faqs/faq.cfm?id=29\&t=6>

ExxonMobil (2015), Annual Report ExxonMobil Corp. 2014, Form 10-K.

González R., José (2013), "Refinerías en México. Retos y posturas para una revisión en el ámbito legislativo", Centro de Estudios Sociales y de Opinión Pública, Documento de Trabajo núm. 160.

IEA (2014), "Medium Term Market Report: Market Analysis and Forecasts to 2019”, OCDE/EIA, June.

(2015), "Medium-Term Oil Market Report 2015", OCDE/EIA.

Instituto Mexicano para la Competitividad A.C. (IMCO) (2013), "Índice de Competitividad Internacional 2013, Nos cambiaron el mapa: México ante la Revolución Energética del siglo xxı", México.

Iyer, C.G. (2015), Impact of Entrepreneur on the Sectorial System of Innovation: Case Study of the Indian Crude Oil Refining Industry, Technol. Fo- 
recast. Soc. Change (consultado el 17 de noviembre de 2015), disponible en $<$ http://dx.doi.org/10.1016/j.techfore>

Mundo Ejecutivo Express (2015), "Robo en ductos de Pemex suman 27000 barriles diario" (consultado el 9 de noviembre de 2015), disponible en $<$ http://mundoejecutivoexpress.mx/politica/2015/09/23/robo-ductospemex-suman-27000-barriles-diarios>

opec (2014), Annual Statistical Bulletin, opep, Vienna Austria. (2015a), World Oil Outlook, oper, Vienna Austria, October. (2005b), The Refining Issue, Opep Bulletin, vol. xxxvı, No. 6, pp. 13-14.

Pemex (2013), Principales elementos del Plan de Negocios de Pemex y sus Organismos Subsidiarios, 2014-2018, México.

Pemex (2014), Annual Report 2014, Form 20-F. (2015a), Boletín de Prensa No. 118.

(2015b), Informe de Sustentabilidad 2014, México.

Periódico El Economista (2015), "Pemex sacrifica proyectos de refinación por recorte al gasto" (consultado el 12 de diciembre de 2015) disponible en $<$ http://eleconomista.com.mx/industrias/2015/02/17/pemex-sacrificaproyectos-refinacion-recorte-gasto>

Phillip 66 (2015), Annual Report Phillip 66 Corp. 2014, Form 10-K.

Poder Ejecutivo Federal (2002), Programa Sectorial de Energía 2001-2006, Secretaría de Energía, México.

(2013), Plan Nacional de Desarrollo 2013-2018, Secretaría de Energía, México.

Revista Contralinea (2013), "Contrato Colectivo de Trabajo de Pemex, más privilegios a cúpula sindical" (consultado el 18 de febrero de 2016) disponible en <http://www.contralinea.com.mx/archivo-revista/index.php/2013/ 08/11/contrato-colectivo-de-trabajo-de-pemex-mas-privilegios-cupulasindical/>

Romo Rico, Daniel (2011), Pemex, origen, evolución y perspectiva, México, Pemex-IPN.

Secretaría de Energía (2007), Prospectiva de Petrolíferos 2007-2016, México. (2014), Prospectiva de Petróleo y Petrolíferos, 2014-2028, México. (2016), Diagnóstico de la Industria de Petrolíferos en México, México.

The White House (2012), "Obama Administration Finalizes Historic 54.5 MPG Fuel Efficiency Standards", press release, August 28, 2012 (consultado el 18 de enero de 2016) disponible en <http://www.whitehouse. gov/the-press-office/2012/08/28/obama-administration-finalizes-historic$545 \mathrm{mpg}$-fuel-efficiency-standard> 
Daniel Romo

Tesoro (2015), Annual Report Tesoro Corp. 2014, Form 10-K.

Valero (2015), Annual Report Valero Energy Corp. 2014, Form 10-K. 